\title{
The Breakthrough Generations Study: design of a long-term UK cohort study to investigate breast cancer aetiology
}

\author{
AJ Swerdlow ${ }^{*, 1}$, ME Jones', MJ Schoemaker', J Hemming', D Thomas', J Williamson ${ }^{2,3}$ and A Ashworth ${ }^{2}$ \\ 'Section of Epidemiology, Institute of Cancer Research, Sir Richard Doll Building, 15 Cotswold Road, Sutton, Surrey SM2 5NG, UK; ${ }^{2}$ Breakthrough Breast \\ Cancer Research Centre, Institute of Cancer Research, Fulham Road, London SW3 6JB, UK
}

\begin{abstract}
BACKGROUND: The rationale, design, recruitment and follow-up methods are described for the Breakthrough Generations Study, a UK cohort study started in 2003, targeted at investigation of breast cancer aetiology.

METHODS: Cohort members have been recruited by a participant referral method intended to assemble economically a large general population cohort from whom detailed questionnaire information and blood samples can be obtained repeatedly over decades, with high completeness of follow-up and inclusion of large numbers of related individuals. 'First-generation' recruits were women contacted directly, or who volunteered directly, to join the study. They nominated female friends and family, whom we contacted, and those who joined ('second generation') nominated others, reiterated for up to 28 generations.

RESULTS: The method has successfully been used during 2003-20 I I to recruit I I 2049 motivated participants with a broad geographic and socioeconomic distribution, aged 16-102 years, who have completed detailed questionnaires; $92 \%$ of the participants gave blood samples at recruitment. When eligible, $2 \frac{1}{2}$ years after recruitment, $>98 \%$ completed the first follow-up questionnaire. Thirty percent are first-degree relatives of other study members.

CONCLUSION: The 'generational' recruitment method has enabled recruitment of a large cohort who appear to have the commitment to enable long-term continuing data and sample collection, to investigate the effects of changing endogenous and exogenous factors on cancer risk.

British Journal of Cancer (201 I) 1 05, 91।-917. doi: I0.1038/bjc.201।.337 www.bjcancer.com

Published online 6 September 2011
\end{abstract}

(c) 20II Cancer Research UK

Keywords: cohort study; breast cancer; aetiology

Cohort studies have been responsible for establishing almost all of the known causes of cancer (Breslow and Day, 1987). Such studies have tended, however, to be expensive, time-consuming and difficult to carry out well with high completeness of follow-up. As a consequence, practical considerations have constrained the studies that have been conducted.

Breast cancer is by far the most common cancer in women in the United Kingdom and many other Western countries. Although many risk factors have been found over the last 50 years, investigation of its aetiology has been difficult, in part because of the very long period of life over which aetiological factors appear to act, ranging from childhood, perhaps even prenatally, to well after menopause. Difficulty has also arisen from the key role of factors that cannot be ascertained by questionnaire or retrospectively - notably breast density, sex hormone and probably growth-related hormone concentrations - and the complexity of the aetiology of this tumour, involving a multiplicity of genetic susceptibility traits, environmental and behavioural factors, as well as endogenous hormones. We therefore reasoned that to conduct a

\footnotetext{
*Correspondence: Professor Al Swerdlow;

E-mail: anthony.swerdlow@icr.ac.uk

${ }^{3}$ Current address: Department of Research Oncology, Kings College London, Guy's Hospital, London SEI 9RT, UK

Received I9 May 20 II; revised 2 August 201 I; accepted 2 August 201 I; published online 6 September 2011
}

comprehensive investigation of breast cancer aetiology, a cohort design is needed, in particular to ascertain factors that cannot be ascertained retrospectively, but also to avoid recall bias and imprecision. The study would need to recruit some participants from as young an age as possible, gain blood samples and detailed questionnaire information on exposures, both at recruitment and periodically thereafter, and have a high follow-up rate and the ability and consent to retrieve recorded data and stored biological specimens. Many of these factors depend on gaining a high degree of commitment of the study subjects, such that they are willing to give the time and effort to donate blood samples, complete followup questionnaires, allow access to their records and materials, and stay engaged in the study. We therefore wished to develop a recruitment method that would find and involve committed individuals.

\section{MATERIALS AND METHODS}

\section{Recruitment}

The Breakthrough Generations Study is a long-term prospective cohort study focussed on potential aetiological factors for breast cancer in women. It has received appropriate ethics committee approval. The study cohort consists of volunteer women aged 16 years or older at entry. They have been recruited from the general population of the British Isles, and were initially identified from three principal sources. The first source was women on the 
list of supporters of Breakthrough Breast Cancer, the charity who funded the study. Secondly, as a consequence of publicity, especially at the launch of the study in September 2004, tens of thousands of women contacted the study team to express their interest via our website and telephone lines, or less often by personal contact. Thirdly, women who joined the study were asked if they would nominate female friends and family aged 16 years and older who they thought might also be interested in joining. The probands could discuss the study with the nominees, or not, as they wished, before nominating them.

Women from all these sources were mailed an initial invitation letter and information booklet explaining the study, and a form asking whether they would like to be sent the study pack, without obligation. Those who assented were mailed the study pack, which included a questionnaire, information booklet, consent form and blood pack. If they chose to take part, the women completed and returned to us the consent form and questionnaire. A freephone number was provided to answer any queries. For the blood sample, the majority took their blood pack to their general practice, where a $27-\mathrm{ml}$ blood sample was taken and the cohort member then posted the blood tubes, at ambient temperature, to our laboratory. Some blood samples $(<10 \%)$ were taken by nurses working for the study, and some samples were taken by others - for instance, phlebotomists at the subject's workplace, nurses or doctors in hospitals, or nurses or doctors otherwise known to the subjects.

For hormone and certain other analyses, it is highly desirable that blood samples be centrifuged, aliquoted and frozen down on the day of receipt. Thus, unlike a study solely collecting questionnaires, which can mail tens of thousands of questionnaires within a few days and then store the returns and process them subsequently over several months, a study collecting plasma needs to receive samples at as constant a rate as possible, avoiding peaks that exceed the laboratory's capacity, or dips that waste laboratory staff time and overhead costs. To achieve this, as we could not control when subjects chose to donate blood and post it, we calibrated the mailing-out rates to generate as constant a flow as possible, based on our experience of the time distribution of response times obtained in the initial stages of the study, allowing for day of the week and season of the year.

When premenopausal women joined the study, they were asked that if possible they should present for venipuncture at a standard point in their menstrual cycle, 7 days before they expected their next period, but if this was not possible, nevertheless to send a blood sample taken when practical. When the subjects returned their blood samples, they also returned a form on which they had recorded several variables relevant to the sample, including the time and date the sample was taken, the time the subject woke on that day, the date of their last menstrual period, and whether they were taking various medicines and supplements.

\section{Recruitment questionnaire}

The study questionnaire asked about demographic variables, and factors known or suspected to affect the risk of breast cancer, including reproductive and menstrual history, exogenous hormone intake, exercise, benign breast disease, alcohol, smoking, some dietary variables, chest exposure to ionising radiation, variables related to the woman's own birth, childhood growth and puberty, height, weight, melatonin-related variables (e.g., shift work, exposure to light at night), occupation, socioeconomic variables, family history of cancer, and chronic diseases. We included questions on childhood and adolescent exposures and behaviours, as well as those in adulthood, and where appropriate (e.g., alcohol consumption, exercise) asked about these variables by age, to allow exposure histories to be built. For the same reason, information on selected exposures is being updated in follow-up questionnaires. The questionnaire also asked the women to self-measure, or ask others to measure for them, certain anthropometric variables weight, waist circumference, hip circumference and arm span.

Information was sought within the questionnaire, and the participant's informed consent was sought, to enable medical and other relevant records to be located and examined for validation of certain data, and to obtain exposure details that were not possible to obtain from the questionnaires. For instance, information and consent were collected to allow examination of the woman's own birth records, mammograms and treatments. The questionnaire was designed for the subjects' responses to be read by Optical Character Reading (OCR) software via a scanner (Readsoft, 2011), and, where possible, it asked the respondent to give exact replies to numerical questions, in order to maximise data detail, rather than offering multiple-choice boxes to select between pre-formed ranges. The software provides quality control of the OCR by two methods. First, any characters that the software has uncertainty in reading, or is unable to read, are flagged up to a clerical operative to read and enter the correct character. About $8 \%$ of completed fields need clerical intervention. Secondly, for alphabetic and numeric characters, but not for ticks, the software shows the operator all of the responses the subject has made for that character (e.g., all the $7 \mathrm{~s}$, all the $8 \mathrm{~s}$, etc.), for the operator to inspect and decide whether they are all consistent and have been read correctly. In addition, for certain key variables such as date of birth, the software was programmed to compel the operator to read and check the response for each study subject. We also programmed range and validity checks that show the operator for correction, invalid or unlikely values of characters or combinations of characters (e.g., values for 'month' greater than 12).

\section{Blood sample processing}

When blood samples taken as described above were received at the laboratory, the samples were centrifuged and divided into $0.5-\mathrm{ml}$ barcoded 'straws' for storage, using a MAPI machine (Cryobiosystem, 2011). This provided approximately 27 straws of plasma and 6 straws of buffy coat per participant, which enable $0.5-\mathrm{ml}$ aliquots to be retrieved for analysis without thawing and refreezing of the remainder of the material. The samples were cooled to $-80^{\circ} \mathrm{C}$ in a freezer and subsequently transferred for long-term storage into liquid-nitrogen tanks, where they are held in the vapour phase at $<-180^{\circ} \mathrm{C}$. The samples for each subject were split and stored in two different sites, 40 miles apart, for security. Each straw is barcoded and recorded on a database that we have constructed so that its location and use can be tracked. DNA is extracted from the buffy coat ad hoc as needed, using Qiagen DNA Blood Mini Kits (Qiagen, Valencia, CA, USA); about $30 \mu \mathrm{g}$ of DNA is obtained per straw, on average. Unnormalised stock DNA samples are then stored at $-80^{\circ} \mathrm{C}$ in individual $2 \mathrm{D}$ barcoded tubes, and are normalised later when required.

\section{Follow-up}

Follow-up data on site-specific cancer incidence, other major disease occurrence, breast disease and cause-specific mortality are obtained via several sources. First, we receive spontaneous reports from cohort members about the occurrence of breast and other cancers, and from their husbands/partners or other relatives about deaths. Secondly, annual newsletters are sent to the cohort members, and if these are returned as undeliverable, we then ascertain vital status using the methods described below and (if alive) track a current address via the sources below. The newsletter also includes a tear-off sheet for participants to notify us if they have changed name or address. Thirdly, at intervals of about $2 \frac{1}{2}$ years since enrolment, participants are sent follow-up questionnaires that ask, inter alia, about illness since the last questionnaire and which, effectively, ascertain their vital status. (These questionnaires also ascertain changes in exposure variables since entry into the study 
and extend the range of questions about exposures (e.g., when new scientific questions arise), and the mailing can be used to obtain repeat blood samples). It is intended that follow-up questionnaires will continue for the next 40 years and longer.

When women are lost to postal follow-up at any of the above points, they are traced via several potential sources, namely (i) e-mail, (ii) telephone, (iii) 'flagging' on the National Health Service Central Registers (NHSCRs), virtually complete population registers of England, Wales and Scotland on which cancers, deaths, emigrations and other exits are recorded and can therefore be notified to authorised researchers, (iv) the NHS Strategic Tracing Service (now Personal Demographics Service), an online system derived in part from the NHSCR, that enables address changes and deaths in England and Wales to be looked up and (v) enquiries via the friend or family member who recommended the woman as a potential study subject.

When deaths are ascertained via the above sources, we obtain copies of death certificates to ascertain the cause of death. When cancers are reported we obtain diagnostic confirmation and details from cancer registry data and/or by writing to the appropriate clinicians. We routinely obtain histology information from these sources, gain grade information for a large minority and are now trying to obtain hormone receptor information for incident and recent prevalent cases.

\section{Family relationships}

The original referral forms for nomination of potential new participants asked the relationship of the nominee to the nominator, and the first follow-up questionnaire included a question on whether, to their knowledge, any relatives of the participant had joined the study. If either of these sources indicated a potential relationship, records were cross-matched to determine whether both of the relatives had actually joined the study. This should have given virtually complete family linkage, because each link was potentially reported twice, by each member of the relationship.

\section{RESULTS}

\section{Recruitment}

Using the above recruitment methods, we obtained the names of 372524 women potentially interested in joining the study, of whom 237203 (64\%) replied positively to the initial invitation letter and were sent the study pack. Of these women, 112049 (47\%) have returned the questionnaire and become study members.

Table 1 shows descriptive characteristics of the cohort: $49 \%$ were aged $45-64$ at recruitment, $42 \%$ younger and $9 \%$ older; $46 \%$ were in the highest socioeconomic group (based on place of residence; CACI, 2009), but there were appreciable numbers in all socioeconomic groups. Likewise, the largest proportion lived in the South of England (43\%), but with substantial numbers from other parts of the United Kingdom. The cohort were somewhat more concentrated in middle age, high socioeconomic status and the South of England compared with the national population.

Figure 1 shows the operation and lag times of the generational recruitment method for the first eight generations of participants. For simplicity of display, the first round of mailing dates are normalised as day 0; in practice they were spread over several calendar years. Each generation lagged the one before it by a mean of 87 days; this lag was slightly shorter at older ages ( 73 days for those aged 65 and older) than at younger (97 days for those aged under 35 ), and in later generations (68 days for generations $\geqslant 20$ ) than earlier (91 days in generation 2), but in all instances was in the range $65-100$ days.

On average, each woman participating in the study nominated 2.76 candidates to join the study, of whom 0.81 candidates on
Table I Descriptive characteristics of cohort participants and UK general population

\begin{tabular}{|c|c|c|c|}
\hline \multirow[b]{2}{*}{ Characteristic } & \multicolumn{2}{|c|}{ Participants in cohort } & \multirow{2}{*}{$\begin{array}{l}\text { UK population } \\
\text { Percent }^{\mathbf{a}}\end{array}$} \\
\hline & Number & Percent & \\
\hline \multicolumn{4}{|l|}{ Age at entry to study (years) } \\
\hline $16-24$ & 5286 & 4.7 & 14.0 \\
\hline $25-34$ & 17579 & 15.7 & 15.6 \\
\hline $35-44$ & 23839 & 21.3 & 18.5 \\
\hline $45-54$ & 26865 & 24.0 & 15.7 \\
\hline $55-64$ & 27920 & 24.9 & 14.4 \\
\hline $65-102$ & 10560 & 9.4 & 21.8 \\
\hline \multicolumn{4}{|c|}{ Socioeconomic status (ACORN score) at entry ${ }^{\mathrm{b}}$} \\
\hline A (highest) & 51568 & 46.0 & 25.4 \\
\hline B & 12641 & 11.3 & 11.5 \\
\hline C & 31875 & 28.5 & 27.4 \\
\hline $\mathrm{D}$ & 8899 & 7.9 & 13.8 \\
\hline E (lowest) & 6424 & 5.7 & 21.2 \\
\hline Unclassified $^{c}$ & 112 & 0.1 & - \\
\hline Outside ACORN coverage ${ }^{d}$ & 530 & 0.5 & - \\
\hline \multicolumn{4}{|l|}{ Region of residence at entry } \\
\hline South of England & 48641 & 43.4 & 34.5 \\
\hline East of England & 12443 & 11.1 & 9.3 \\
\hline Midlands & 17873 & 15.9 & 15.9 \\
\hline North of England & 20711 & 18.5 & 23.8 \\
\hline Scotland & 7290 & 6.5 & 8.5 \\
\hline Northern Ireland & 653 & 0.6 & 2.8 \\
\hline Wales & 3908 & 3.5 & 4.9 \\
\hline Isle of Man, Channel Islands & 530 & 0.5 & 0.4 \\
\hline \multicolumn{4}{|l|}{ Family members in study } \\
\hline Mother or daughter(s) & 22814 & 20.4 & - \\
\hline Sister(s) & 15157 & 13.5 & - \\
\hline Aunt(s) & 3028 & 2.7 & - \\
\hline Grandmother(s) & 341 & 0.3 & - \\
\hline Total & 112049 & 100.0 & 100.0 \\
\hline
\end{tabular}

ancluding Isle of Man and Channel Islands for age and region of residence, but excluding those locations for ACORN score. Data from various years after 2000, depending on data availability. Age data are for females; the other data are for both sexes combined. ACORN data are for ages 16-74 from CACl (2009); the other data are for ages $\geqslant 16$ calculated from various government statistical sources. bocioeconomic score based on postcode of residence (CACl, 2009). 'Primarily communal residences such as student halls, and newly built (post-Census) properties. ${ }^{\mathrm{d}}$ Resident in Isle of Man and Channel Islands, for which ACORN coding is not applicable.

average, joined. The longest generational chain had reached 28 generations by the time we stopped the generational recruitment process. The nominations for recruitment were skewed, however: $85 \%$ of the names were put forward by $30 \%$ of the participants, and $48 \%$ of the participants suggested no names. The average number of nominations was similar across the generations and by geographical area, but increased with higher socioeconomic status (2.9 for the highest, 2.3 for the lowest) and was greatest for women aged 45-54 years (3.0) and less at younger and older ages than this (e.g., 2.2 for ages $16-24 ; 1.9$ for age 65 and older) (these differences are highly significant, $P<0.001$ ).

Recruitment ratios (i.e., the ratio of the number of nextgeneration to the number of previous, 'proband', generation participants) increased with age of the proband, from 0.46 for probands aged 16-24 to 0.94 for those aged 55-64, and then decreased slightly (Table 2 ). The ratio was also generally greater for higher than for lower socioeconomic class probands $(0.91$ for the highest group, 0.55 for the lowest), but generally showed little variation by geographical area.

The generational recruitment mechanism had the interesting tendency that it produced, after several generations, recruits 


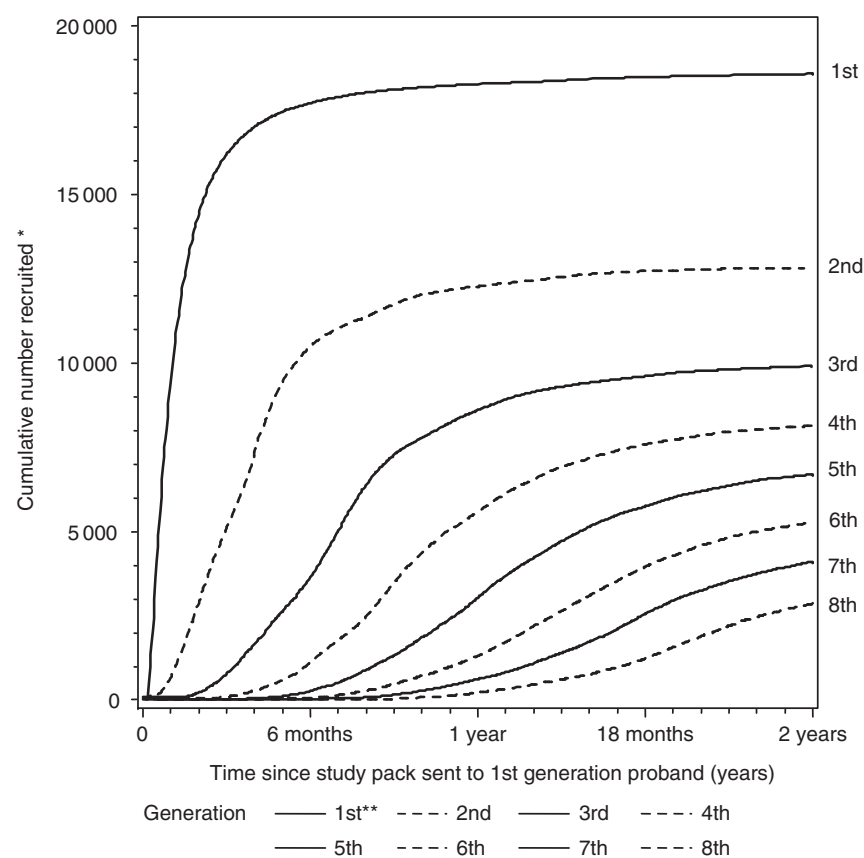

Figure I Time course of recruitment of cohort participants, by generation. Ist generation = probands approached directly by the study investigators; 2 nd generation $=$ women recommended by the first generation; 3rd generation $=$ women recommended by the second generation, etc. *Recruitment is taken as return of a completed questionnaire. ***For practical reasons, in the early part of the study, when publicity provided more recruits than could be processed adequately without delays, a block of first-generation recruits were not asked to nominate further-generation recruits: these women are excluded from the figure.

who were of a fairly similar age and socioeconomic distribution irrespective of the initial distribution of the probands (Tables 3 and 4). Thus, for instance, first-generation probands aged under 35 years produced at the fourth and subsequent generations an intake among whom $18 \%$ were aged under $35,45 \%$ aged $35-54$ and $37 \%$ aged $\geqslant 55$, while first-generation probands aged 65 or older produced $a \geqslant 4$ th generation whose distribution was $14 \%, 43 \%$ and $43 \%$, respectively. This tendency of the recruitment mechanism was less true, however, for geographical area of residence, especially for Scotland: first-generation probands from Scotland provided $55 \%$ of $\geqslant 4$ th-generation recruits from Scotland, whereas first-generation probands from elsewhere gave rise to only $5.5 \%$ of recruits from Scotland in the $\geqslant 4$ th generation.

\section{Blood samples}

Of the women who returned a questionnaire, 102778 (92\%) also gave a blood sample. There are now $>3.2$ million straws in storage. Including the pilot study, recruitment occurred during 2003-2011, but mainly during 2005-2007, at a rate of about $400-700$ per week. The generational recruitment method enabled invitation mailings to be sent out (and names to mail to be available) as a continuous mechanism, promptly as interest was expressed, but with a constant and controlled flow of work through the laboratory. The arrival rate of blood samples never exceeded 760 per week (229 per day). Seventy one percent of samples arrived on the day of venipuncture or the next day, $13 \%$ the day after that, $8 \%$ after 3 days, $5 \%$ after 4 days, and the remaining $4 \%$ later (we have found that for female sex hormones, a 2-day lag has only modest effects on concentrations (Jones et al, 2007)).
Table 2 Recruitment ratios (number of new participants recruited directly by proband), by characteristics of proband

\begin{tabular}{|c|c|c|c|}
\hline $\begin{array}{l}\text { Characteristic } \\
\text { of proband }\end{array}$ & $\begin{array}{l}\text { Number of } \\
\text { probands }\end{array}$ & $\begin{array}{l}\text { Number of } \\
\text { recruits }^{\mathrm{a}}\end{array}$ & $\begin{array}{l}\text { Recruitment } \\
\text { ratio }\end{array}$ \\
\hline \multicolumn{4}{|l|}{ Age at entry to study } \\
\hline $16-24$ & 3941 & 1808 & 0.46 \\
\hline $25-34$ & 13390 & 9460 & 0.71 \\
\hline $35-44$ & 19961 & 14679 & 0.74 \\
\hline $45-54$ & 23721 & 20984 & 0.88 \\
\hline $55-64$ & 25388 & 23976 & 0.94 \\
\hline $65-74$ & 8501 & 6427 & 0.76 \\
\hline $75-102$ & 1286 & 771 & 0.60 \\
\hline \multicolumn{4}{|c|}{ Socio-economic status (ACORN score) at entry ${ }^{b}$} \\
\hline A (highest) & 45133 & 40984 & 0.91 \\
\hline B & 10851 & 8533 & 0.79 \\
\hline C & 27088 & 20299 & 0.75 \\
\hline $\mathrm{D}$ & 7314 & 4944 & 0.68 \\
\hline E (lowest) & 5257 & 2882 & 0.55 \\
\hline Unclassified $^{c}$ & 88 & 56 & 0.71 \\
\hline Outside ACORN coverage $^{d}$ & 457 & 407 & 0.90 \\
\hline \multicolumn{4}{|l|}{ Region at entry } \\
\hline South & 42775 & 34935 & 0.82 \\
\hline East of England & 10333 & 8489 & 0.82 \\
\hline Midlands & 15339 & 12894 & 0.84 \\
\hline North of England & 17425 & 13675 & 0.78 \\
\hline Scotland & 6055 & 4852 & 0.80 \\
\hline Northern Ireland & $47 \mid$ & 272 & 0.59 \\
\hline Wales & 3333 & 2581 & 0.78 \\
\hline Isle of Man, Channel Islands & 457 & 407 & 0.90 \\
\hline Total & 96188 & 78105 & 0.81 \\
\hline
\end{tabular}

${ }^{a}$ New participants recruited directly by proband. ${ }^{b}$ Socioeconomic score based on postcode of residence (CACl, 2009). 'Primarily communal residences such as student halls, and newly built (post-Census) properties. ${ }^{\text {d}}$ Resident in places (largely Isle of Man, Channel Islands) for which ACORN coding is not applicable.

\section{Family relationships}

The generational recruitment method produced a large number of study participants who were related to other participants. In total, $22977(21 \%)$ were mothers or daughters of other study members, 15252 (14\%) were sisters, including 109 dizygotic and 158 monozygotic twin pairs, and 6991 (6\%) were second-degree relatives. There were 15183 families in the study, with an average of 2.3 study members per family. At recruitment, 13333 (12\%) of participants reported that their mother had had breast cancer, and 4163 (4\%) reported at least one sister with breast cancer; the comparable figures for recruits aged $50-64$ were $12 \%$ and $5 \%$.

\section{Prevalent breast cancer at study entry}

The initial invitation to join the study was open to all women resident in the United Kingdom aged 16 and above, whether or not they had previously had breast cancer. As a consequence, the study includes 6407 women who, the questionnaire showed, had had breast cancer or DCIS before entry into the study. These subjects will for some purposes be analysed separately - for instance, for immediate analysis of the genetics of breast cancer (Fletcher et al, 2011), and for cohort analysis of risk factors for second primary, but not first primary, breast cancer. For first primary analyses their reporting of risk factors is potentially biased by their awareness of the prevalent tumour.

\section{Follow-up}

Follow-up questionnaires are being sent to the cohort on a rolling basis: each individual is contacted at fixed periods $\left(2 \frac{1}{2}, 5,7 \frac{1}{2}\right.$, etc., 
Table 3 Age distribution of $\geqslant 4$ th-generation recruits to the cohort for different age groups of first-generation probands

Distribution (\%) of age (years) at recruitment in $\geqslant 4$ th-generation recruits

\begin{tabular}{|c|c|c|c|c|c|c|c|}
\hline \multirow[b]{3}{*}{ Age (years) at recruitment of Ist generation ${ }^{a}$} & & & & & & & \\
\hline & \multirow[b]{2}{*}{$16-34$} & \multirow[b]{2}{*}{$35-44$} & \multirow[b]{2}{*}{$45-54$} & \multirow[b]{2}{*}{$55-64$} & \multirow[b]{2}{*}{$65-102$} & \multicolumn{2}{|c|}{ Total } \\
\hline & & & & & & $\%$ & Number \\
\hline Ist generation aged $35-44(n=4427)$ & 15.8 & 22.4 & 24.8 & 27.1 & 10.0 & 100.0 & 8038 \\
\hline Ist generation aged $45-54(n=4349)$ & 16.2 & 19.8 & 26.8 & 26.3 & 10.9 & 100.0 & 16284 \\
\hline Ist generation aged $55-64(n=4134)$ & 16.4 & 19.4 & 24.7 & 28.8 & 10.7 & 100.0 & 17456 \\
\hline Ist generation aged $65-102(n=1540)$ & 14.2 & 17.6 & 25.3 & 29.7 & 13.2 & 100.0 & 4095 \\
\hline
\end{tabular}

${ }^{a}$ i.e. the probands at the start of the recruitment chains.

Table 4 Socioeconomic distribution of $\geqslant 4$ th-generation recruits to the cohort for different socioeconomic groups of first-generation probands

\begin{tabular}{|c|c|c|c|c|c|c|c|}
\hline & A (highest) & B & C & D & E (lowest) & \multicolumn{2}{|c|}{ Total } \\
\hline I st generation A (highest) $(n=747$ |) & 50.3 & 10.2 & 28.0 & 7.0 & 4.5 & 100.0 & 27314 \\
\hline I st generation $B(n=2752)$ & 50.0 & 11.9 & 26.8 & 6.9 & 4.3 & 100.0 & 9063 \\
\hline All ist generation $(A-E)(n=18752)$ & 49.7 & 10.7 & 27.9 & 7.1 & 4.7 & 100.0 & 50287 \\
\hline
\end{tabular}

aSocioeconomic score based on postcode of residence (CACl, 2009). bi.e. the probands at the start of the recruitment chains.

years) related to her original recruitment date. This produces, as for the recruitment, an even workload over time for mailings, especially for laboratory work to process follow-up blood samples without delay. Not all recruits have yet reached their first $\left(2 \frac{1}{2}\right.$-year) follow-up date, and the figures below are therefore based on the first 90000 recruits who have passed this point, plus the further 12 months that has proved necessary to reach a maximum response rate through tracing and reminders. Three hundred and thirty-nine $(0.4 \%)$ of these subjects have died. Of the 89661 remaining, $88596(98.8 \%)$ have contributed a follow-up questionnaire, $315(0.4 \%)$ have emigrated without follow-up questionnaire and $750(0.8 \%)$ others have not yet returned their questionnaire. The follow-up questionnaire percentage among those who have not died is similar by generation, greater for high $(99.1 \%)$ than for low $(97.7 \%)$ socioeconomic groups, and somewhat greater at ages $45-64(99.4 \%)$ than at younger $(98.4 \%)$ or older $(98.0 \%)$ ages. Follow-up information on vital status has been obtained for $99.5 \%$ of the cohort.

\section{DISCUSSION}

Most large cohorts designed to investigate cancer aetiology have been recruited by the investigators contacting potential subjects directly - for instance, specific occupational groups (e.g., Doll and Hill, 1954; Bernstein et al, 2002; Nurses Health Study, 2011), members of the general population (e.g., van den Brandt et al, 1990; Riboli and Kaaks, 1997; Kolonel et al, 2000; UK Biobank, 2011), or health-care groups or trial participants (Buring and Hennekens, 1992; The ATBC Cancer Prevention Study Group, 1994; The Million Women Study Collaborative Group, 1999; Prorok et al, 2000; Hays et al, 2003). The American Cancer Society have recruited three cohorts by asking volunteers each to recruit a number of their acquaintances (Thun et al, 2000). To our knowledge, however, there have not been any large cohorts recruited by multiple 'generations' of participant referrals.

We had hoped, and the evidence so far supports this, that recruiting volunteers in this way would enable us to find particularly committed participants, in order to enable several design aspects that would require such commitment and that are difficult to achieve in large cohort studies. First, we needed a method that could recruit participants on a large scale, economically, and at a controlled rate so that blood samples could be processed by the laboratory on the day of receipt. The generational method appears to be able to do this. Although we ceased generational recruitment at 112000 subjects, this was deliberate, based on resource availability, and there was no sign that we would 'run out' of eligible women. Probands in late generations were providing just as many next-generation recruits as had earlier generations. Thus, the recruitment was just short of self-sustaining over time if no new first-generation subjects had been added, and with a small addition of extra first-generation recruits from time to time could have been perpetuated almost indefinitely. The average cost per recruit (including laboratory costs, and including the costs for women approached who did not join the study) was $£ 50$ (\$81).

Secondly, we wanted to obtain in the study questionnaire a great amount of detail on exposures in order to be able to analyse precise relationships and to investigate dose and duration response effects. Also, collection of exact numerical data rather than multiple-choice ranges gave maximum flexibility for future pooled analyses with other cohorts, if they have only collected grouped data. The questionnaire included more than 900 fields on 44 pages, and was filled in with a high degree of completeness (Morris et al, 2010). Similarly, we wished to collect blood specimens, both to obtain sufficient quantities of good-quality DNA to enable genetic and epigenetic analyses over the coming decades, and also to obtain plasma, particularly for hormone analyses, as sex hormones and probably growth-related hormones are critical to breast cancer 
aetiology (Hankinson et al, 2004). Blood samples were collected for $>92 \%$ of the subjects, again reflecting their high degree of commitment.

Although a few large cohort studies have managed to collect updated questionnaire information every year or two on exposures in their cohort (e.g., Bernstein et al, 2002; Hays et al, 2003; Nurses' Health Study, 2011), many have not, and the few collections of longterm repeat blood samples have been of a very limited scale (Nurses' Health Study, 2011; Women's Health Initiative, 2011). Such information and samples are likely to be critical, however, to unravelling the aetiology of breast cancer and evaluating the effects of changing behaviours and environments, as the aetiological factors span most or all of a lifetime, from before menarche, perhaps prenatally, to after menopause (Hankinson et al, 2004). Obtaining repeat questionnaires and blood samples (and hence being able to assay hormone levels) from a high proportion of participants over decades is therefore important, but also likely to be extraordinarily difficult. So far, the generational recruitment method appears to have found cohort members sufficiently motivated to enable this. The study design includes, subject to the constraints of funding, repeated blood sampling periodically over the years.

It is also desirable to be able to obtain recorded information (e.g., diagnostic and therapeutic information from GP and hospital records) and images (e.g., mammograms) and to retrieve and use stored biological specimens (e.g., pathology specimens from tumours enabling histological and molecular classification of tumours). The information and written permission given by the study subjects have enabled all of these, with a good success rate in locating and obtaining the data and specimens (such acquisition is not yet complete, but currently is about $60-70 \%$ ).

The choice of age group included in cohorts investigating the aetiology of breast cancer or many other cancers is almost inevitably a compromise between the scientific desire for prospectively gained exposure data and plasma samples from a young age, and the practical need for the study to accrue cancer outcomes, and hence results, sufficiently rapidly to be fundable. In practice, many cancer-oriented cohorts have recruited subjects from about age 50 and older, (van den Brandt et al, 1990; The Million Women Study Collaborative Group, 1999; Kolonel et al, 2000; Prorok et al, 2000; Schatzkin et al, 2001; Hays et al, 2003; White et al, 2004; Nurses' Health Study, 2011), and uncommonly they have recruited down to age 25 or so (Bernstein et al, 2002; Nurses' Health Study, 2011). We recruited at all ages from 16, in order to include both older subjects, who give more rapid results, and younger ones, who in the long term will enable more accurate, prospectively collected, exposure data and plasma samples through the reproductive years. Ideally, to encompass measurement of risk factors for breast cancer at all potentially relevant periods, a study would recruit prenatally and then follow up subjects throughout life, but we did not attempt this, and restricted the study to those age 16 or older at entry, because of the ethical difficulties in gaining consent to enrol children (or fetuses) for lifetime follow-up, the potential losses to adult follow-up if individuals had in practice been consented by their parents and not themselves, and the practical difficulties in obtaining and maintaining support and funding for a cancer study that would produce no direct cancer results for 30 or 40 years.

Focussing the design on investigation of breast cancer aetiology has the advantage of avoiding the compromises necessary in cohorts intended to investigate the causes of many diseases simultaneously (Elliott and Peakman, 2008), and probably adding to the commitment of the participants and hence to follow-up rates. It has also increased the extent of recruitment of high-risk individuals, because women with relatives with breast cancer have an incentive to join, and hence increased the power of the study, especially for genetic analyses (based on follow-up of the first 85000 participants without prior breast cancer, we estimate that breast cancer risk in the cohort is about 1.6 times that in the general population). Thus, the proportion of our recruits aged $50-$ 64 at entry whose mother $(12 \%)$ or sister $(5 \%)$ had had breast cancer was much greater than in relatively unselected women of the same ages undergoing breast screening in the United Kingdom (6 and 4\%, respectively (The Million Women Study Collaborative Group, 1999)). It has the limitation, however, that although we are collecting data to enable investigation of other morbidity and mortality outcomes, the relevance of the exposure data available will diminish the more that the aetiology of the outcome is unlike that for breast cancer. Thus, for instance, the study data and samples are highly relevant to ovarian cancer or benign breast disease aetiology, but much less so to, say, diabetes. To maintain the focus on breast cancer, use of the samples is prioritised to this objective, and samples will only be used to investigate other outcomes if this does not divert them from breast cancer research.

The sources of the study subjects - Breakthrough Breast Cancer supporters, volunteers in response to publicity, and friends and family of existing members - are not a random sample of the general population. Those who are friends and family of the existing cohort members are also, on average, more similar to the probands than would be expected in members of the general population, which could be a defect if they were intended as controls in a casecontrol study, but is not a bias for a cohort design. Cohort studies do not need to represent the general population in order to be valid, and indeed many of the most valuable have been solely comprised of a particular group (e.g., doctors (Doll and Hill, 1954) or nurses (Nurses' Health Study, 2011)). Nevertheless, narrow target groups can sometimes reduce the heterogeneity of exposures and hence power. The generational recruitment method proved surprisingly able to generate participants from a wide spectrum of society - the age and socioeconomic distribution, and to a lesser extent geographic distribution, of late-generation recruits to our cohort was wide-ranging and was about the same irrespective of the selective distribution of the proband generation.

The Generations study is currently in its early stages, and hence published outputs to date have been based on the data and blood samples gathered at recruitment rather than at follow-up. Sufficient follow-up is now accumulating to enable cohort analyses in the near future, and we are keen on collaborative uses of the materials, both as part of pooling projects and as collaborations with particular investigators (e.g., Murray et al, 2011). We are constructing linked databases that hold all of the questionnaire and biological sample data, including those generated by collaborators outside our Institute, to maximise the availability and scope of data available for future analyses. For laboratory analyses and other variables that require intensive efforts to obtain data (e.g., mammographic density), the assays and data acquisition are on a nested case-control basis. An Oversight Committee is in place to vet and decide upon the uses of the biological samples. We estimate that the power of the study is such that, for example, by 2020 for an exposure with $20 \%$ prevalence, the study will have $96 \%$ power to detect at $P<0.05$ a relative risk of 1.2 for breast cancer incidence, $85 \%$ power to detect a relative risk of 1.3 for oestrogen receptor-negative breast cancer and $78 \%$ power to detect a relative risk of 1.4 for triple-negative breast cancer.

In summary, the 'generational' recruitment method has enabled recruitment of a cohort of $>110000$ women of all adult ages, who have provided detailed questionnaires and blood samples, and a high response rate to follow-up thus far, and who appear to have the commitment to the study to enable long-term high-quality data and biological samples to continue to be collected over decades to come.

\section{ACKNOWLEDGEMENTS}

We thank Breakthrough Breast Cancer and the Institute of Cancer Research for support and funding of the study. We are very grateful to the study participants for the time, effort and 
commitment they have given, and to the doctors, nurses and other health-care staff who have taken blood samples and sent information. We thank Craig Higgins, Susan Laing, Nadia Mudie, Rosie Cooke, Emily McFadden, Danielle Morris, Nicola Johnson, Mitchell Dowsett, Richard Houlston, Nicholas Orr, Sarah Chilcott-Burns, Gemma Simpson, Katarzyna Tomczyk, Craig Allen, Clare Smith, Radhika Reddy, Ha Nguyen, Mark Alston, Montserrat GarciaClosas, Usha Menon, Ian Jacobs, the members of the study Advisory Committee and Oversight Body, Alison Butlin, Margo Pelerin, Jill Wood, Tracy Gardener, Alison Hart, Jean Hoare, Gloria Seaward, Sandra Drummond, Sharon Self, Joanne Micic, Susan Blackmore,

\section{REFERENCES}

Bernstein L, Allen M, Anton-Culver H, Deapen D, Horn-Ross PL, Peel D, Pinder R, Reynolds P, Sullivan-Halley J, West D, Wright W, Ziogas A, Ross RK (2002) High breast cancer incidence rates among California teachers: results from the California Teachers Study (United States). Cancer Causes Control 13: 625-635

Breslow NE, Day NE (1987) Statistical Methods in Cancer Research. Volume II The Design and Analysis of Cohort Studies IARC Scientific Publications No. 82. International Agency for Research on Cancer: Lyon, France

Buring JE, Hennekens CH (1992) The Women's Health Study: summary of the study design. J Myocardial Ischemia 4: 27-29

CACI (2009) ACORN Directory. CACI: London http://www.caci.co.uk/ acorn-classification.aspx

Cryobiosystem (2011) http://www.cryobiosystem-imv.com/BIOBANKING/ Produits/Equipments/MAPI/tabid/265/Default.aspx

Doll R, Hill AB (1954) The mortality of doctors in relation to their smoking habits; a preliminary report. $\mathrm{Br}$ Med J 1: $1451-1455$

Elliott P, Peakman TC (2008) The UK Biobank sample handling and storage protocol for the collection, processing and archiving of human blood and urine. Int J Epidemiol 37: 234-244

Fletcher O, Johnson N, Orr N, Hosking FJ, Gibson LJ, Walker K, Zelenika D, Gut I, Heath S, Palles C, Coupland B, Broderick P, Schoemaker M, Jones M, Williamson J, Chilcott-Burns S, Tomczyk K, Simpson G, Jacobs KB, Chanock SJ, Hunter DJ, Tomlinson IP, Swerdlow A, Ashworth A, Ross G, dos Santos Silva I, Lathrop M, Houlston RS, Peto J (2011) Novel breast cancer susceptibility locus at 9q31.2: results of a genome-wide association study. J Natl Cancer Inst 103: 425-435

Hankinson SE, Colditz GA, Willett WC (2004) Towards an integrated model for breast cancer etiology: the lifelong interplay of genes, lifestyle, and hormones. Breast Cancer Res 6: 213-218

Hays J, Hunt JR, Hubbell FA, Anderson GL, Limacher M, Allen C, Rossouw JE (2003) The Women's Health Initiative recruitment methods and results. Ann Epidemiol 13: S18 - S77

Jones ME, Folkerd EJ, Doody DA, Iqbal J, Dowsett M, Ashworth A, Swerdlow AJ (2007) Effect of delays in processing blood samples on measured endogenous plasma sex hormone levels in women. Cancer Epidemiol Biomarkers Prev 16: 1136-1139

Kolonel LN, Henderson BE, Hankin JH, Nomura AM, Wilkens LR, Pike MC, Stram DO, Monroe KR, Earle ME, Nagamine FS (2000) A multiethnic cohort in Hawaii and Los Angeles: baseline characteristics. Am J Epidemiol 151: 346 - 357

Morris DH, Jones ME, Schoemaker MJ, Ashworth A, Swerdlow AJ (2010) Determinants of age at menarche in the UK: analyses from the Breakthrough Generations Study. Br J Cancer 103: 1760-1764
Gillian Moore, Kim Sibley, Beverley Smith, Sharon Squires, Robert McCann, Chi Nguyen, Catherine Thomas, Deborah Hogben, Margaret Snigorska, the Facilities team at the ICR, and in particular Jonathan Kipling, Cathy Scivier, Steven Surridge, Richard Garfield and Jeffrey Barley for their input to and advice on the study and its design. We also thank the NHS Information Centre; the General Register Office for Scotland; the Cancer Registries of England, Wales, Scotland and Northern Ireland; the Health and Social Care Services Organisation, Northern Ireland; Sue Groves, Jersey; and Keith Robilliard, Guernsey. We acknowledge NHS funding to the NIHR Biomedical Research Centre.

Murray A, Bennett CE, Perry JR, Weedon MN, Jacobs PA, Morris DH, Orr N, Schoemaker MJ, Jones M, Ashworth A, Swerdlow AJ (2011) Common genetic variants are significant risk factors for early menopause: results from the Breakthrough Generations Study. Hum Mol Genet 20: $186-192$

Nurses' Health Study (2011) http://www.channing.harvard.edu/nhs/

Prorok PC, Andriole GL, Bresalier RS, Buys SS, Chia D, Crawford ED, Fogel R, Gelmann EP, Gilbert F, Hasson MA, Hayes RB, Johnson CC, Mandel JS, Oberman A, O'Brien B, Oken MM, Rafla S, Reding D, Rutt W, Weissfeld JL, Yokochi L, Gohagan JK (2000) Design of the Prostate, Lung, Colorectal and Ovarian (PLCO) Cancer Screening Trial. Control Clin Trials 21: 273S-309S

Readsoft (2011) http://www.readsoft.com/

Riboli E, Kaaks R (1997) The EPIC Project: rationale and study design. European Prospective Investigation into Cancer and Nutrition. Int $J$ Epidemiol 26(Suppl 1): S6-S14

Schatzkin A, Subar AF, Thompson FE, Harlan LC, Tangrea J, Hollenbeck AR, Hurwitz PE, Coyle L, Schussler N, Michaud DS, Freedman LS, Brown CC, Midthune D, Kipnis V (2001) Design and serendipity in establishing a large cohort with wide dietary intake distributions: the National Institutes of Health-American Association of Retired Persons Diet and Health Study. Am J Epidemiol 154: 1119-1125

The ATBC Cancer Prevention Study Group (1994) The alphatocopherol, beta-carotene lung cancer prevention study: design, methods, participant characteristics, and compliance. Ann Epidemiol 4: $1-10$

The Million Women Study Collaborative Group (1999) The Million Women Study: design and characteristics of the study population. Breast Cancer Res 1: $73-80$

Thun MJ, Calle EE, Rodriguez C, Wingo PA (2000) Epidemiological research at the American Cancer Society. Cancer Epidemiol Biomarkers Prev 9: $861-868$

UK Biobank (2011) http://www.ukbiobank.ac.uk/docs/UKBProtocol_000.pdf van den Brandt PA, Goldbohm RA, van't Veer P, Volovics A, Hermus RJ, Sturmans F (1990) A large-scale prospective cohort study on diet and cancer in The Netherlands. J Clin Epidemiol 43: 285-295

White E, Patterson RE, Kristal AR, Thornquist M, King I, Shattuck AL, Evans I, Satia-Abouta J, Littman AJ, Potter JD (2004) VITamins And Lifestyle cohort study: study design and characteristics of supplement users. Am J Epidemiol 159: 83-93

Women's Health Initiative (2011) http//www.whiscience.org/about/ biospecimen.php

This work is published under the standard license to publish agreement. After 12 months the work will become freely available and the license terms will switch to a Creative Commons Attribution-NonCommercial-Share Alike 3.0 Unported License. 